\title{
CONSIDERACIONES ACERCA DE LA CONCEPCIÓN KANTIANA DE LA LIBERTAD EN SENTIDO POLÍTICO
}

\author{
Ileana P. Beade \\ UNR CONICET \\ Ileanabeade@yahoo.com.ar
}

\begin{abstract}
Resumen
En este trabajo analizamos dos definiciones kantianas de la libertad política que han sido consideradas como definiciones antagónicas: una de ellas parece aproximar a Kant a la corriente del liberalismo moderno; la otra daría lugar, en cambio, a una interpretación republicana del pensamiento político kantiano. El análisis de ambas definiciones permitirá mostrar que éstas no resultan necesariamente incompatibles.
\end{abstract}

Palabras clave: Kant, libertad política, liberalismo, republicanismo.

\begin{abstract}
In this paper we shall analyze two Kantian definitions of political freedom which have been considered mutually exclusive: one of them would allow us to consider Kant as an exponent of the liberal tradition; the other would lead to a republican interpretation of Kant's political thought. The analysis of both definitions will show that they are not necessarily incompatible.
\end{abstract}

KEYWORDS: Kant, Political Freedom, Liberalism, Republicanism.

\section{Introducción}

Dn los Principios metafísicos de la doctrina del derecho (primera parte de la Metafísica de las costumbres), Kant define la libertad del ciudadano como la capacidad "de no obedecer a ninguna otra ley más que a aquella a la que ha dado su consentimiento" (Kant, Ak. VI, 314), definición que evoca principios reivindicados por la tradición republicana, tales como los de autonomía y autolegislación ${ }^{1}$. Sin

En Sobre la paz perpetua (Kant, Ak. VIII, 341-386), Kant define la libertad en términos análogos: "Mi libertad exterior (jurídica) hay que explicarla, más bien, de la siguiente manera: como la facultad de no obedecer ninguna ley exterior sino en tanto y en cuanto he podido darle mi consentimiento" (Kant, Ak. VIII, 350). 
embargo, en Teoría y práctica², el filósofo define la libertad política a través de la siguiente fórmula:

"Nadie me puede obligar a ser feliz a su modo (tal como él se imagina el bienestar de otros hombres), sino que es lícito a cada uno buscar su felicidad por el camino que mejor le parezca, siempre y cuando no cause perjuicio a la libertad de los demás para pretender un fin semejante, libertad que puede coexistir con la libertad de todos según una posible ley universal (esto es, coexistir con ese derecho del otro)" (Kant, Ak. VIII, 290).

Si la primera definición de la libertad invoca el derecho del ciudadano a obedecer solo aquellas leyes en las que pueda ver reflejada su propia voluntad legisladora, la segunda definición remite, en cambio, al derecho de cada individuo de procurar su bienestar del modo que considere más conveniente (sin que ello implique un perjuicio para la libertad de otros, pues la libertad de cada uno ha de coexistir con la libertad de los demás bajo una ley universal (Kant, Ak., VIII, 298)).

Haciendo uso de la distinción entre libertad negativa y libertad positiva propuesta por Berlin ${ }^{3}$, los intérpretes del pensamiento político kantiano han intentado establecer la filiación del pensador alemán con diversas tradiciones del pensamiento político: quienes consideran a Kant como un defensor de la libertad positiva (frecuentemente asociada con la concepción de la libertad reivindicada por la tradición republicana) se han centrado en la primera definición de la libertad a la que hemos aludido; quienes intentan inscribir al autor en las filas de los partidarios de la libertad negativa (generalmente identificada con la concepción liberal de

$2 \quad$ Kant, Über den Gemeinspruch: Das mag in der Theorie richtig sein, taugt aber nicht für die Praxis (Ak., VIII, 273-313).

3 Berlin define a la libertad negativa como "el hecho de no ser obstaculizado por otros", contraponiéndola a la libertad positiva en tanto capacidad de autodeterminación racional del individuo (cf. Berlin 1992, p. 218). El autor señala que estas diversas concepciones de la libertad se hallan en abierto conflicto: si aquellos que reivindican la libertad negativa aspiran a limitar la esfera de acción del Estado (o de cualquier otra autoridad) con el fin de resguardar el ámbito privado, aquellos que reivindican la libertad positiva establecen la participación en la vida pública como una condición esencial de la libertad. Adoptando la distinción propuesta por Berlin, Bobbio define la libertad negativa como "la situación en la cual un sujeto tiene la posibilidad de obrar o de no obrar, sin ser obligado a ello o sin que se lo impidan otros sujetos [...]. La libertad negativa suele llamarse también «libertad como ausencia de impedimentos» o «libertad como ausencia de constricción»" (Bobbio 1995, pp. 97-98). El autor señala que la libertad positiva remite, en cambio, a aquella situación en la que un sujeto "tiene la posibilidad de orientar su voluntad hacia un objetivo, de tomar decisiones, sin verse determinado por la voluntad de otros" (op. cit., p. 100). Si bien existen importantes diferencias en el planteo de los autores que apelan a la distinción entre libertad negativa y libertad positiva, en términos generales la libertad negativa es entendida como la libertad del individuo frente al Estado, y la libertad positiva, como la libertad del individuo como parte activa del Estado. 
la libertad) se atienen, por el contrario, a la segunda definición. En este trabajo, proponemos analizar en detalle la primera definición, con el fin de mostrar que, pese a su aparente afinidad con principios reivindicados por el republicanismo moderno (en particular, con el republicanismo rousseauniano), Kant se aparta de esta corriente de pensamiento al establecer el alcance y los límites del consentimiento a las leyes. El análisis pormenorizado de diversos aspectos implicados en la idea de consentimiento (tales como la noción de representación, la cuestión de la resistencia a la autoridad o la concepción de la ciudadanía) permitirá mostrar que Kant ha despojado a esta fórmula republicana (de raigambre rousseauniana) de su sentido originario. De allí que las citadas definiciones de la libertad política no resulten, en definitiva, tan opuestas como suele considerárselas.

A continuación, intentaremos determinar, en primer lugar, si la definición kantiana de la libertad como facultad de obedecer solo a aquellas leyes a las que se ha dado consentimiento implica un consentimiento efectivo (o bien, puramente táctico) de los individuos con respecto a las leyes públicas (en otras palabras, procuraremos establecer si el principio de consentimiento a las leyes exige o no una participación directa del ciudadano en el proceso legislativo). En segundo lugar, analizaremos las limitaciones que la restricción kantiana de la ciudadanía implica para la idea de consentimiento a las leyes. Por último, consideraremos la posición del autor respecto de la posibilidad de los individuos de oponer resistencia legítima a las leyes a las que no hayan dado su consentimiento expreso. Este análisis permitirá mostrar que la definición kantiana de la libertad como derecho a obedecer solo a aquellas leyes a las que se ha dado consentimiento no refleja el espíritu democrático implicado en la concepción republicana de la libertad, ya que Kant establece límites estrictos a la idea de consentimiento, al exigir la delegación irrevocable de la soberanía en favor del representante, al restringir la ciudadanía a un número limitado de individuos y, por último, al reivindicar la máxima de la obediencia absoluta a la autoridad constituida.

\section{Consecuencias del principio kantiano de representación para la noción del "consentimiento a las leyes"}

Hemos señalado que el análisis de la definición kantiana de la libertad como capacidad del ciudadano de "no obedecer a ninguna otra ley más que a aquella a la que ha dado su consentimiento" exige considerar en detalle de qué manera entiende Kant la idea de un consentimiento a las leyes o, en otras palabras, qué consecuencias tiene, para el filósofo, la exigencia de que las leyes públicas deban fundarse en la voluntad legisladora de los individuos que integran la sociedad civil ${ }^{4}$. Lo primero que

4 Refiriéndose a la distinción entre la libertad civil y la libertad propia del hombre en "estado de naturaleza", Kant alude a la voluntad legisladora en virtud de la cual el individuo decide instituir un orden civil y someterse a leyes públicas: "no puede decirse que el 
ha de establecerse es si esta voluntad legisladora se expresa o no de manera directa e inmediata en el proceso legislativo, lo cual exige considerar de qué manera entiende Kant el principio de representación.

En el $§ 46$ de los Principios metafísicos de la doctrina del derecho, el filósofo afirma que "el poder legislativo solo puede corresponder a la voluntad unida del pueblo" (Kant, Ak. VI, 313). Sin embargo, la tarea legislativa no compete, en sentido estricto, al pueblo, sino a sus representantes. Haciendo referencia a las características propias de la forma republicana de gobierno (considerada por Kant como la única forma legítima de gobierno), el autor establece que "toda verdadera república es -y no puede ser más que- un sistema representativo del pueblo, que pretende, en nombre del pueblo y mediante la unión de todos los ciudadanos, cuidar de sus derechos a través de delegados" (Kant, Ak. VI, 341) ${ }^{5}$. Kant considera que la forma republicana de gobierno es incompatible con el régimen democrático, porque en este último -al ser administrado el gobierno por el pueblo en su totalidad- no puede darse el principio básico del republicanismo, a saber, el principio de representación:

"De las tres formas de Estado, la democracia es, en el sentido propio de la palabra, necesariamente un despotismo, porque funda un poder ejecutivo donde todos deciden sobre y, en todo caso, también contra uno (quien, por tanto, no da su consentimiento), con lo que todos, sin ser todos, deciden; esto es una contradicción de la voluntad general consigo misma y con la libertad" (Kant, Ak. VIII, 352).

Dado que el gobierno republicano no exige una determinada forma de soberanía, aquél podría darse tanto en un régimen autocrático como en un régimen aristocrático; sin embargo, no podría darse en un régimen democrático, pues el republicanismo es -como acabamos de indicar- una forma representativa de gobierno, y la democracia

Estado, el hombre en el Estado, haya sacrificado a un fin una parte de su libertad exterior innata, sino que ha abandonado por completo la libertad salvaje y sin ley, para encontrar de nuevo su libertad en general, íntegra, en la dependencia legal, es decir, en un estado jurídico; porque esta dependencia brota de su propia voluntad legisladora" (Kant, Ak. VI, 315-316).

5 Cabe señalar que el republicanismo no constituye, para Kant, un régimen de gobierno, sino una forma de la soberanía, es decir, un cierto modo de ejercer el poder político en la conducción del Estado. Así establece, en Sobre la paz perpetua, una distinción entre las formas de la soberanía y las formas de gobierno: "las formas de un Estado (civitas) pueden clasificarse por la diferencia en las personas que poseen el supremo poder del Estado o por el modo de gobernar al pueblo, sea quien fuere el gobernante. Con la primera vía se denomina realmente la forma de la soberanía (forma imperii) y solo hay tres formas posibles, a saber, la soberanía la posee uno solo, o algunos relacionados entre sí, o todos los que forman la sociedad civil conjuntamente (autocracia, aristocracia y democracia, poder del príncipe, de la nobleza, del pueblo). La segunda vía es la forma de gobierno (forma regiminis) y se refiere al modo como el Estado hace uso de la plenitud de su poder [...]: en este sentido la constitución es o republicana o despótica" (Kant, Ak. VIII, 352). 
-tal como Kant la entiende (es decir, como democracia directa) - no da cabida al principio de representación (Kant, Ak. VIII, 353). Más aún: el autor considera que cuanto menor sea el número de individuos que ejercen el poder en el Estado, mayor será el grado en que pueda verse representada la voluntad del pueblo y mayores serán, entonces, las posibilidades de alcanzar un gobierno republicano.

En síntesis, la forma de soberanía no es lo decisivo para que un Estado pueda ser gobernado conforme a los principios del republicanismo, y dado que "el pueblo tiene más interés [...] en el modo de gobierno que en la forma de Estado" (Kant, Ak. VIII, 353), "mandar autocráticamente y, pese a ello, gobernar de un modo republicano, es decir, con el espíritu del republicanismo y por analogía con él, es lo que hace a un pueblo sentirse verdaderamente satisfecho con su constitución" (Kant, Ak. VII, $87)^{6}$.

Estas observaciones permiten constatar que la idea kantiana del consentimiento a las leyes no implica una participación directa de todos los individuos que integran la comunidad en el proceso legislativo. Tampoco la noción de voluntad general implica-en el marco del pensamiento político kantiano- un compromiso con los principios democráticos que Rousseau deduce de esa idea ${ }^{7}$. Si bien Kant invocará, en sus escritos, el concepto rousseauniano de voluntad general, reconociéndolo como un principio fundamental de toda constitución política legítima, no asumirá, sin embargo, las consecuencias radicales que el ginebrino deduce de esta idea. En efecto, Kant concibe la voluntad general como una suerte de ideal regulativo, esto es, como un principio que no implica la adopción de determinados procedimientos legislativos, ni supone convocar a todos los miembros de la comunidad para la elaboración de las leyes públicas. También, en sentido puramente formal, invoca Kant otro de los principios fundamentales del pensamiento rousseauniano, a saber: la idea de contrato social:

"Mas he ahí un contrato originario, el único sobre el que se puede fundar entre
los hombres una constitución civil, legítima para todos sin excepción, el único
sobre el que se puede erigir una comunidad. Pero respecto de este contrato [...],
en tanto que coalición de cada voluntad particular y privada, dentro de un pueblo,
para constituir una voluntad comunitaria y pública (con el fin de establecer
una constitución, sin más, legítima), se trata de una mera idea de la razón que
tiene, sin embargo, su indudable realidad (práctica), a saber, la de obligar a todo

6 Astorga señala que la impugnación kantiana del régimen democrático, y su caracterización del mismo como una forma de despotismo, denotan la influencia de Hobbes en el pensamiento político de Kant (cf. Astorga 1996, pp. 81ss.).

7 Rousseau establece, en efecto, que la voluntad general no admite ser delegada ni, por tanto, representada por otro: "solo la voluntad general puede dirigir las fuerzas del Estado según el fin de su institución, que es el bien común [...]. Digo pues, que no siendo la soberanía más que el ejercicio de la voluntad general, jamás puede enajenarse, y que el soberano, que no es más que un ser colectivo, no puede ser representado más que por sí mismo; el poder puede muy bien transmitirse, pero no la voluntad" (Rousseau 1996, p. $32)$. 
legislador a que dicte sus leyes como si éstas pudieran haber emanado de la voluntad unida de todo un pueblo, y a que considere a cada súbdito, en la medida en que éste quiera ser ciudadano, como si hubiera expresado su acuerdo con una voluntad tal. Pues ahí se halla la piedra de toque de toda ley pública" (Kant, Ak. VIII, 297).

Estas observaciones permiten afirmar que las ideas de voluntad general y de contrato no implican, en este marco, el reconocimiento de derechos inalienables del pueblo, sino que son asumidas, en todo caso, como criterios que permiten al legislador dictar leyes tales que hubiesen podido ser aceptadas por la voluntad unida de todo un pueblo:

"Si una ley es de tal índole que resultara imposible a todo un pueblo otorgarle su conformidad [...], entonces no es legítima; pero si es simplemente posible que un pueblo se muestre conforme con ella, entonces constituirá un deber tenerla por legítima, aun en el supuesto de que el pueblo estuviese ahora en una situación o disposición de pensamiento tales que, si se le consultara al respecto, probablemente denegaría su conformidad" (Kant, Ak. VIII, 297).

Para que una ley sea considerada legítima (y pueda reclamar el consentimiento de aquellos que se someten a ella), no es preciso que sea el pueblo reunido en asamblea quien dicte tal ley, ni tampoco es necesario que éste preste su consentimiento efectivo: si una ley es de tal índole que resulte imposible que todo un pueblo pueda otorgarle su aprobación, entonces no es legítima, pero con que sea solo posible que alguna vez el pueblo prestara su conformidad a dicha ley establecida, entonces ésta puede ser considerada justa (y el derecho de juzgar acerca de tal posibilidad no compete, según Kant, al pueblo sino al propio legislador, como veremos en el siguiente apartado).

A partir del análisis precedente, podemos concluir que, pese a su reivindicación de las ideas rousseaunianas de voluntad general y de contrato, Kant atribuye a esas ideas un sentido formal, al concebirlas como principios regulativos reservados para uso discrecional del legislador ${ }^{8}$. Quienes suscriben una interpretación "en clave republicana" del pensamiento político kantiano suelen desatender el sentido puramente formal en que Kant se apropia de las ideas políticas de Rousseau; y en lo que respecta puntualmente a la definición kantiana de la libertad como capacidad de no obedecer a ninguna otra ley más que a aquella a la que ha dado su consentimiento, no reparan en el hecho de que el consentimiento del individuo respecto de las leyes no implica una participación directa del pueblo en el procedimiento legislativo. Si se considera, por otra parte, que los súbditos no tienen medios de oponer resistencia legítima a las leyes establecidas (aun cuando no pudiesen prestar consentimiento a dichas leyes), es forzoso reconocer que la adscripción de Kant a las filas del republicanismo resulta, cuanto menos, problemática.

8 Para un análisis comparativo del pensamiento político de Kant y Rousseau, véase: Kaufman 1997, pp. 25-52; Rubio-Carracedo 1998, pp. 52-65. 


\section{El problema de la resistencia a la autoridad (a propósito de la reivindicación kantiana de la obediencia absoluta)}

Hemos establecido que la idea del consentimiento a las leyes implicada en la definición kantiana de la libertad que aquí nos ocupa, no exige una participación directa del pueblo en el proceso de la elaboración de las leyes públicas, pues éste interviene en dicho proceso solo indirectamente, a través de representantes. Una consecuencia fundamental que Kant deduce de la idea de representación es que, al delegar la soberanía en favor del representante, el pueblo renuncia a la posibilidad de recobrar el poder que ha sido transferido. Esto implica, básicamente, que no podrá oponer resistencia legítima a las decisiones del gobernante:

"Un ser dotado de libertad [...] no puede ni debe reclamar, conforme al principio formal de su arbitrio, ninguna otra clase de gobierno para el pueblo al que pertenece sino aquella en la cual todos sean colegisladores [...]. Pero ese derecho solo es una idea cuya realización se ve subordinada a la condición de que sus medios concuerden siempre con la moralidad, algo que el pueblo no debe transgredir jamás. La realización de esta idea no debe producirse mediante la revolución, que siempre es injusta" (Kant, Ak. VII, 86).

Kant rechaza todo derecho del súbdito a oponer resistencia activa a la autoridad de las leyes (o del poder político que las respalda), aun en el caso de que las leyes no hayan sido promulgadas en conformidad con el principio de voluntad general, y aun cuando el poder político que administra las leyes fuese ejercido de manera despótica (atentando así contra derechos inalienables de los súbditos). Los argumentos invocados por el autor a fin de justificar su impugnación de todo derecho de resistencia convergen en la idea de que todo acto que resista a la autoridad constituye una amenaza para la subsistencia del estado de derecho:

"Contra la suprema autoridad legisladora del Estado no hay [...] resistencia legítima del pueblo; porque solo la sumisión a su voluntad universalmente legisladora posibilita un estado jurídico; por tanto, no hay ningún derecho de sedición, aun menos de rebelión, ni mucho menos existe el derecho de atentar contra su persona [...] so pretexto de abuso del poder" (Kant, Ak. VI, 320).

"El poder que en el Estado da efectividad a la ley no admite resistencia (es irresistible), y no hay comunidad jurídicamente constituida sin tal poder, sin un poder que eche por tierra toda resistencia interior, pues ésta acontecería conforme a una máxima que, universalizada, destruiría toda constitución civil, aniquilando el único estado en que los hombres pueden poseer derechos en general. De ahí se sigue que toda oposición contra el supremo poder legislativo, toda incitación que haga pasar a la acción el descontento de los súbditos, todo levantamiento que estalle en rebelión, es el delito supremo y más punible en una comunidad, porque destruye sus fundamentos" (Kant, Ak. VIII, 299).

En los Principios metafísicos del derecho se establece que los tres poderes que constituyen el Estado no admiten resistencia alguna por parte del súbdito: el poder 
legislativo es irreprochable, el poder ejecutivo, irresistible y las sentencias judiciales, inapelables (cf. Kant, Ak. VI, 316). La razón de ello es que, una vez que el pueblo ha delegado el poder de promulgar las leyes, no retiene el derecho de emitir juicio acerca del modo en que sus representantes hagan uso del poder que se les ha transferido:

"aun cuando aquel poder y su agente haya llegado a violar el contrato originario y a perder con eso, ante los ojos del súbdito, el derecho a ser legislador por autorizar al gobierno para que proceda de modo absolutamente despótico (tiránico), sin embargo, no le está permitida al súbdito resistencia alguna en forma de contraviolencia. La razón de ello es que, en una constitución cívica ya existente, el pueblo no sigue teniendo el derecho de emitir constantemente un juicio sobre cómo debe ser administrada tal constitución" (Kant, Ak. VIII, 299-300)9 .

Kant sostiene que la acción revolucionaria destruye los fundamentos de la comunidad "porque tal modo de proceder (una vez aceptado como máxima) torna insegura toda constitución jurídica e introduce un estado de absoluta ausencia de ley (status naturalis) en el que todo derecho cesa, cuanto menos, de surtir efectos" (Kant, Ak. VIII, 301). El fenómeno revolucionario es identificado aquí, pues, con la disolución misma del Estado de derecho ${ }^{10}$.

Los argumentos invocados por Kant a fin de justificar su condena a toda revolución (incluso a aquella que reivindicase derechos inalienables del ciudadano) remiten a la contradicción implicada en la idea de una constitución jurídica que reconociese en sí misma el derecho a resistir sus leyes, atentando así contra su propia vigencia). En los Principios metafísicos de la doctrina del derecho, el autor señala que, en el caso de que existiese una ley pública que autorizara la resistencia del pueblo,

"la legislación suprema contendría en sí misma la determinación de no ser la suprema y de convertir al pueblo como súbdito, en uno y el mismo juicio, en soberano de aquel al que está sometido; lo cual es contradictorio. Esta contradicción se evidencia al preguntar: ¿quién entonces debería ser juez en este conflicto entre el pueblo y el soberano?" (Kant, Ak. VI, 320).

$9 \quad$ He aquí un punto que marca una distancia irreductible entre las ideas políticas de Kant y de Rousseau (para quien la soberanía popular es indelegable) y, por otra parte, la proximidad del pensador alemán con el modelo político hobbesiano.

10 Pese a su condena de la revolución, Kant fue un simpatizante entusiasta de la Revolución Francesa, a la que llegó a considerar como un signo inequívoco del progreso moral del género humano (cf. Reiteración de la pregunta de si el género humano se halla en constante progreso hacia lo mejor, Kant, Ak. VIII, 84-87). Respecto de la posición ambigua que el filósofo asume ante la revolución, Arendt señala que, si bien desde una perspectiva jurídica y moral Kant ha de condenar todo acto subversivo, desde una perspectiva histórico-filosófica ciertas revoluciones admiten ser interpretadas como signos del progreso histórico (cf. Arendt 2003, pp. 90ss). Una interpretación similar de esta cuestión puede verse en Foucault 1991, pp. 205ss. 
Si el pueblo estuviese autorizado a emitir juicio respecto del modo en que el gobierno administra la constitución, y considerase injustas las disposiciones del gobernante, ¿quién decidiría, entonces, de qué lado está el derecho? Evidentemente, "ninguno de los dos podría hacerlo, porque sería juez en su propia causa. Luego, por encima del jefe tendría que haber aún otro jefe que decidiera entre aquél y el pueblo, lo que resulta contradictorio" (Kant, Ak. VIII, 300). Este argumento se reitera en otros escritos kantianos. En Teoría y práctica, Kant afirma, en efecto:

"que la constitución contuviera una ley para tal caso, una ley que autorizara a derrocar la constitución vigente - de la cual dimanan todas las leyes particulares- en el supuesto de que el contrato sea quebrantado, sería una clara contradicción, porque entonces habría de contener también un contrapoder públicamente constituido y, por ende, sería preciso todavía un segundo Jefe de Estado que amparase los derechos del pueblo frente al primero, e incluso un tercero que decidiese entre ambos para dirimir de parte de cuál de ellos está el derecho" (Kant, Ak. VIII, 303).

Un poder público que, bajo ciertas circunstancias, autorizase la desobediencia del pueblo no podría constituirse como poder soberano. De allí que Kant rechace todo derecho de resistencia. En una constitución -señala- no puede admitirse

\begin{abstract}
"ningún artículo que permita a un poder estatal oponer resistencia al jefe supremo, por tanto, limitarle, en el caso de que viole las leyes constitucionales. Porque quien debiera restringir el poder estatal ha de tener ciertamente más poder, o al menos el mismo, que aquel cuyo poder resulta restringido; y como señor legítimo que ordena a sus súbditos resistir, ha de poder también defenderlos y juzgarlos legalmente en cada caso y, por tanto, ha de poder ordenar públicamente la resistencia. Pero entonces el jefe supremo no es aquél sino éste; lo cual es contradictorio" (Kant, Ak. VI, 319).
\end{abstract}

Más allá de las contradicciones implicadas en la idea de un derecho de resistencia, el principio subyacente en la condena kantiana de la acción revolucionaria es que "cualquier constitución jurídica, conforme al derecho, aunque sea en pequeño grado, es mejor que ninguna" (Kant, Ak. VIII, 373). No solo es contradictorio otorgar al pueblo el derecho a emitir juicio respecto de la legitimidad de las leyes (o respecto del modo en que el gobierno las ejecuta), sino que además la resistencia a la autoridad constituida implicará la disolución misma del Estado de derecho. A los argumentos de carácter jurídico, Kant añade argumentos morales que establecen el carácter ilegítimo del acto de resistencia: la máxima (principio subjetivo de la acción) en la que se basa dicho acto no resiste el principio de universalidad expresado en la formulación del «imperativo categórico» (“obra solo según aquella máxima por la cual puedas querer que al mismo tiempo se convierta en una ley universal" Kant, Ak. IV, 421). La máxima por la cual me sublevo ante la autoridad no admite ser universalizada, pues no podría querer que aquélla se torne «ley universal» (ya que, en tal caso -sostiene Kant- no podría ser asegurada la vigencia del estado jurídico). El acto de resistencia 
es, por consiguiente, contrario al deber moral, y como tal, no admiten ser justificado bajo ninguna circunstancia ${ }^{11}$.

El análisis de la definición de la libertad como facultad de obedecer solo a aquellas leyes a las que se ha dado consentimiento ha exigido considerar, en primer lugar, en quiénes recae la tarea de dictar las leyes públicas y, en segundo lugar, en qué medida han de ser obedecidas estas leyes. Hemos respondido ya a ambos interrogantes: son los representantes del pueblo -esto es, aquellos en quienes es delegada la soberanía- quienes dictan las leyes que han de regir al conjunto de la sociedad civil; en cuanto al carácter vinculante de las leyes, el pueblo les debe obediencia incondicionada (y también a la autoridad pública que las administra) ${ }^{12}$.

Podemos decir, a partir de lo expuesto, que si bien la definición kantiana de la libertad que hemos analizado evoca nociones básicas de la tradición republicana (tales como los principios de autonomía y de autogobierno), la posición asumida por el filósofo respecto del principio de representación y, por otra parte, respecto del problema de la obediencia, revela que la idea del consentimiento a las leyes no supone, en este marco, un derecho que pueda ser efectivamente reivindicado por el pueblo: al delegar el poder soberano en la figura del representante, el pueblo renuncia al derecho de juzgar cómo deba ser administrado ese poder ${ }^{13}$.

11 Si bien Kant invoca los principios de su filosofía moral a fin de justificar su impugnación de toda resistencia ante la autoridad constituida, diversos autores destacan la tensión existente entre la posición que el filósofo asume frente a la revolución y los principios de su filosofía moral, en particular, aquel que establece que la libertad es un derecho originario (por tanto, inalienable) del hombre. Para un análisis del tratamiento kantiano del problema de la revolución, véase: Wit 1990, pp. 285-305; Savadogo 1999, pp. 319ss.

12 El pueblo no participa directamente en la elaboración de las leyes que han de gobernarlo, ni tiene el derecho de resistir aquellas leyes en las que no vea reflejada su voluntad soberana. He aquí dos puntos que indican la distancia irreductible entre la doctrina política kantiana y el pensamiento de Rousseau: si bien Kant invoca en sus escritos los conceptos rousseaunianos de voluntad general y de contrato social, atribuye a estas nociones un carácter puramente formal, al establecer que estas ideas no pueden ser invocadas por el pueblo a fin de justificar un acto de resistencia (se trata aquí, por tanto, de principios que han de inspirar la tarea del legislador y la administración del gobierno, mas no de ideas que puedan ser reivindicadas por los ciudadanos ante la injusticia de las leyes o del poder público).

13 Si Kant insiste en reiteradas ocasiones en el carácter puramente ideal de la noción de contrato, es porque advierte que, al considerar el contrato como un hecho histórico, ciertos autores intentan reivindicar el derecho del pueblo a revocar el pacto celebrado. Así señala, en los Principios metafisicos del derecho, que, a los efectos de preservar el orden público, es irrelevante que un contrato haya sido efectivamente celebrado entre los miembros de la comunidad: "El origen del poder supremo, considerado con propósito práctico, es inescrutable para el pueblo que está sometido a él: es decir, el súbdito no debe 
Antes de concluir, debemos considerar quiénes poseen, según Kant, el derecho de intervenir (cuanto menos, indirectamente) en el proceso legislativo (lo cual implica el derecho a elegir representantes a través del voto). Esto exige examinar brevemente la concepción kantiana de la ciudadanía, a cuyo análisis dedicamos la sección siguiente.

\section{Ciudadanía y propiedad: acerca de la distinción kantiana entre ciudada- nos activos y pasivos}

Hemos señalado que la libertad en tanto facultad de no obedecer a ninguna otra ley más que a aquella a la que se ha dado consentimiento es un derecho propio del ciudadano. Ahora bien, la condición de ciudadano - que implica el derecho a participar en el proceso legislativo a través de la elección de representantes-solo puede otorgarse -según establece Kant- a aquel que esté en condiciones de ser su propio señor:

"aquel que tiene derecho a voto en la legislación se llama ciudadano [...]. La única cualidad exigida para ello, aparte de la cualidad natural (no ser niño ni mujer), es ésta: que uno sea su propio señor (sui iuris) y, por tanto, que tenga alguna propiedad (incluyendo en este concepto toda habilidad, oficio, arte o ciencia) que le mantenga; es decir, que en los casos en que haya de ganarse la vida gracias a otros, lo haga solo por venta de lo que es suyo, no por consentir que otros utilicen sus fuerzas; en consecuencia, se exige que no sea un sirviente -en el sentido estricto de la palabra- de nadie más que de la comunidad" (Kant, Ak. VIII, 295).

Debe destacarse, ante todo, que la propiedad no se limita aquí a la posesión de bienes materiales, sino que incluye asimismo la posesión de un oficio u actividad cuyo producto haga posible la independencia económica del individuo. Quienes no cumplan con este requisito (como el servidor doméstico o el jornalero, que no pueden vender sino su fuerza de trabajo) "no son miembros del Estado, por lo que tampoco están calificados para ser ciudadanos" (Kant, Ak. VIII, 34). Si las mujeres y los niños no pueden reclamar el rango de ciudadanos en virtud de su incapacidad natural para el ejercicio de los derechos ciudadanos, los que no poseen propiedad (en el sentido

sutilizar activamente sobre este origen, como sobre un derecho cuestionable en lo que se refiere a la obediencia que se le debe [...] no puede ni debe juzgar sino como quiera el actual jefe de Estado (summus imperans). Si ha precedido originariamente como un factum un contrato efectivo de sumisión al jefe de Estado (pactum subiectionis civilis), o si la violencia fue anterior y la ley solo vino después, o bien ha debido seguir este orden, son éstas sutilezas completamente vanas para el pueblo que ya está sometido a la ley civil, y que, sin embargo, amenazan peligrosamente al Estado" (Kant, Ak. VI, 318). 
indicado) tampoco pueden reclamar ese rango, en virtud de su condición socioeconómica.

Esta restricción del derecho de ciudadanía se funda, pues, en el supuesto de que la independencia material constituye una condición sine qua non de la autonomía política. Kant presupone que solo aquellos que posean medios materiales suficientes para garantizar su subsistencia sin necesidad de ponerse al servicio de un señor serán capaces de asumir una posición verdaderamente autónoma en las decisiones políticas. Es por ello que sostiene que no todos los individuos que integran la comunidad tienen derecho a decidir qué leyes han de gobernarlos (si bien todos ellos se hallan igualmente sometidos a las mismas):

“en lo tocante a la legislación misma, todos los que son libres e iguales bajo leyes públicas ya existentes no han de ser considerado iguales, sin embargo, en lo que se refiere al derecho de dictar esas leyes. Quienes no están facultados para ese derecho se hallan sometidos también, como miembros de la comunidad, a la obediencia de esas leyes, con lo cual participan en la protección que de ellas resulta; solo que no como ciudadanos, sino como coprotegidos" (Kant, Ak. VIII, 294).

Aquellos que integran una comunidad regida por leyes civiles son iguales en tanto se hallan igualmente sujetos a las leyes públicas, gozando así de la protección ofrecida por tales leyes. Sin embargo, no todos gozan del derecho a dictar esas leyes; de manera que la igualdad jurídica no implica aquí la participación en el proceso de legislación. Ahora bien, ¿en qué medida puede considerarse libres los coprotegidos por las leyes, teniendo en cuenta que su consentimiento explícito respecto de las leyes no es requerido en modo alguno (pues no participan siquiera de la elección de los representantes en quienes es delegada la tarea legislativa)? Si la libertad es -como sostiene Kant- un derecho originario del hombre (esto es, un derecho que pertenece a todo hombre por su sola condición de tal), lo cierto es que la distinción entre ciudadanos y coprotegidos parece contradecir esa concepción de la libertad ${ }^{14}$.

\section{Algunas consideraciones finales}

El análisis precedente ha intentado mostrar que, si bien la definición kantiana de la libertad como capacidad de obedecer solo a aquellas leyes a las que se ha dado consentimiento evoca principios fundamentales de la tradición republicana -tales como los de autonomía, autogobierno y autolegislación- el análisis de la posición asumida por Kant ante el problema de la representación, el problema de la resistencia a la autoridad y el problema de la extensión y los límites del derecho

14 Diversos intérpretes coinciden en que la restricción kantiana de la ciudadanía se halla en tensión con su concepción de la libertad. Cf. Colomer 1994, pp. 594s.; Abellán 1996, pp. 239-259. 
de ciudadanía, permiten afirmar que el filósofo se aparta de la tradición republicana en aspectos verdaderamente decisivos. Siendo principios fundamentales de esta tradición la idea de una ciudadanía directamente comprometida en los avatares de la vida política, la concepción de la ley como garantía última de la libertad y el rechazo de toda sumisión a un poder despótico (Cf. Béjar 2000, pp. 99ss.), la interpretación del pensamiento político kantiano como expresión del ideario republicano resulta ciertamente problemática.

En lo que respecta puntualmente a la concepción de la libertad reivindicada por el republicanismo, ésta es definida no solo como ausencia de dominación, sino además como participación directa en la vida política (cf. Béjar 2000, pp. 99 ss.), características que no hallamos implicadas en la definición kantiana de la libertad que hemos analizado (en efecto, al afirmar que toda revolución es injusta, y exigir absoluta obediencia al poder constituido, Kant desatiende premisas básicas de la concepción republicana de lo político). De allí que no se dé una auténtica tensión entre las dos definiciones kantianas de la libertad política a las que nos hemos referido en la introducción (definiciones que remiten, en todo caso, a diversos aspectos de la libertad política).

Podría decirse que la definición de la libertad como "capacidad de obedecer solo a aquellas leyes a las que se ha dado consentimiento" establece un principio de legitimidad de las leyes, por cuanto formula un criterio que permite al legislador dictar leyes justas (esto es, "leyes tales que hubiesen podido ser aprobadas por todo un pueblo"). Esta definición alude, pues, al modo en que debe ser pensada la libertad, si atendemos a la relación del individuo con las leyes ${ }^{15}$. La segunda definición kantiana de la libertad política a la que hemos aludido no remite ya a la relación del individuo con las leyes, sino, en todo caso, a la relación del individuo con el Estado. Efectivamente, la libertad es entendida, en este caso, como la capacidad de cada uno de "buscar su felicidad por el camino que mejor le parezca, siempre y cuando no cause perjuicio a la libertad de los demás para pretender un fin semejante" (Kant, Ak. VIII, 290). Si ser libre equivale aquí a no ser determinado por otro en lo que concierne a la búsqueda del bienestar personal, este otro frente al cual se reivindica el derecho de cada uno a decidir acerca de los medios más adecuados para alcanzar su felicidad, no es sino el Estado. De allí que, inmediatamente después de definir la libertad en los términos citados, Kant formule una crítica al gobierno paternalista, aquel que basándose "sobre el principio de la benevolencia para con el pueblo, al modo de un padre para con sus hijos", considera a los súbditos "como niños menores de edad, incapaces de distinguir lo que les es verdaderamente beneficioso o perjudicial" (Kant,

15 La respuesta de Kant a esta problemática fundamental de la filosofía política es que, en el marco de la sociedad civil (regulada por leyes positivas), solo puedo considerarme libre en la medida en que obedezco leyes que hayan sido dictadas en correspondencia con el principio de una voluntad autolegisladora (es decir, con los principios de contrato y de voluntad general, pues solo esta correspondencia puede garantizar la legitimidad de las leyes). 
Ak. VIII, 290). Este gobierno paternalista -que atenta contra el derecho del individuo de "buscar su felicidad por el camino que mejor le parezca"- constituye, para Kant, la máxima expresión del despotismo y el mayor obstáculo para la libertad ${ }^{16}$.

$\mathrm{Si}$ en lo que remite a la relación del individuo con las leyes, Kant sostiene que somos libres en la medida en que obedecemos leyes que pudiesen haber sido consentidas por el pueblo (aunque no lo hayan sido efectivamente), respecto de la relación del individuo con el poder público, va a sostener que somos libres en la medida en que el Estado no nos imponga un determinado modo de alcanzar el bienestar individual. Señalamos ya que estas definiciones de la libertad política no resultan contradictorias, sino que remiten, en todo caso, a dos aspectos diversos implicados en la idea de libertad. La primera de ellas ha sido reivindicada por quienes consideran a Kant un exponente del republicanismo moderno ${ }^{17}$; la segunda ha sido destacada por aquellos que lo consideran un pensador liberal ${ }^{18}$. Más allá de la posición que se adopte respecto

16 Bajo un gobierno semejante, los súbditos "se ven obligados a comportarse de manera meramente pasiva, aguardando sin más del juicio del Jefe de Estado cómo deban ser felices y esperando simplemente de su bondad que éste también quiera que lo sean; un gobierno así es el mayor despotismo imaginable (se trata de una constitución que suprime toda libertad a los súbditos, los cuales no tienen entonces absolutamente ningún derecho" (Kant, Ak. VIII, 290-291). En los Principios metafisicos del derecho, Kant caracteriza al gobierno paternalista como un gobierno despótico en el mayor grado posible (cf. Kant, Ak. VI, 316-317), y añade que al Estado no le concierne en modo alguno la felicidad de los súbditos (ni el modo según el cual cada uno de ellos ha de procurársela), sino únicamente la preservación del derecho. El bienestar público -señala- no ha de entenderse como el resultado de la suma de la felicidad de cada individuo, sino que solo ha de determinarse en relación con el derecho de los ciudadanos, "pues no se trata aquí de la felicidad que al súbdito le cabe esperar de una situación o del gobierno de la comunidad, sino simplemente, y ante todo, del derecho que por ese medio debe ser garantizado a cada uno [...]; la salud pública que se ha de tomar en consideración ante todo es precisamente aquella constitución legal que garantiza a cada uno su libertad por medio de leyes, con lo cual cada uno sigue siendo dueño de buscar su felicidad por el camino que mejor le parezca, siempre y cuando no perjudique a esa legítima libertad general" (Kant, Ak. VIII, 298).

17 Cf. Velasco Gómez 2005, pp. 111-112; Bertomeu 2005, pp. 127ss.; Pettit 2004, p. 116; Berlin 1998, p. 219, p. 224n., p. 237; Peña 2005, p. 251. Cabe señalar que, si bien los autores mencionados coinciden en adscribir a Kant a las filas del republicanismo moderno, difieren en su posición respecto de la convergencia que se da, en la obra del filósofo alemán, de influencias que remiten a diversas tradiciones del pensamiento moderno, en particular, del liberalismo y el conservadurismo. Esta convergencia de diversas tradiciones en el pensamiento político kantiano es reconocida, por ciertos intérpretes, como uno de los rasgos típicos de dicho pensamiento (cf. Bielefeldt 1997, pp. 525ss.).

18 Diversos aspectos desarrollados en los escritos políticos de Kant avalan una interpretación liberal de su pensamiento: la importancia decisiva que el filósofo asigna a la libertad de expresión -considerada como "el único paladín de los derechos del pueblo" (cf. Kant, Ak., VIII, 304)-, su concepción de la libertad de comercio como uno de los móviles fundamentales del progreso histórico, su concepción de la propiedad privada como uno de 
a la interpretación republicana o liberal del pensamiento político kantiano, interesa destacar aquí que la primera definición de la libertad se aparta de los principios defendidos por la tradición republicana en aspectos decisivos (a los que hemos aludido en el desarrollo de este trabajo), de manera tal que la distancia que se ha visto entre ambas definiciones no resulta tan amplia como puede parecer en principio.

Por cierto, nuestra breve reflexión acerca de la concepción kantiana de la libertad política no pretende agotar la importante discusión acerca de la filiación de Kant con las corrientes liberal y republicana, sino que se limita simplemente a poner de relieve las tensiones que atraviesan el pensamiento político del filósofo alemán. Considerado por muchos como el filósofo de la libertad, Kant ha sido un promotor de la obediencia absoluta a la autoridad constituida ${ }^{19}$. Celebrado como un defensor de la soberanía del pueblo, ha condenado la democracia, considerándola como una forma de despotismo. Recordado como un promotor de la libertad en tanto derecho originario del hombre, ha restringido el derecho de ciudadanía a aquellos que poseen propiedad. Indudablemente, el reconocimiento de estas tensiones no implica negar los valiosos aportes que Kant realiza en el campo de la filosofía política, ni subestimar la influencia de su filosofía práctica para el desarrollo del pensamiento político moderno y contemporáneo. En todo caso, las tensiones y paradojas implicadas en su reflexión política pueden ser consideradas como un signo inequívoco de su complejidad y su riqueza inagotable.

\section{Referencias bibliográficas}

Abellán, J. (1996), "En torno al concepto de ciudadano en Kant. Comentario de una aporía", en R. Rodríguez Aramayo, J. Muguerza, C. Roldán (eds.), La paz y el ideal cosmopolita de la Ilustración. A propósito del bicentenario de Hacia la paz perpetua de Kant. Madrid: Tecnos, pp. 239-259.

Arendt, H. (2003), Conferencias sobre la filosofía política de Kant. Traducción de C. Corral. Buenos Aires: Paidós.

Astorga, O. (1996), El pensamiento político de Kant. Estudio de su teoría del Derecho $y$ del Estado a partir de la obra de Hobbes. Caracas: Vicerrectorado Académico de la Universidad Central de Venezuela.

los derechos naturales que ha de ser garantizado a través de la fundación del orden civil (Kant, Ak., VI, 237) y, fundamentalmente, sus críticas al gobierno paternalista (y su consiguiente reivindicación de la independencia del ciudadano frente al poder del Estado), avalan dicha interpretación (cf. Bobbio 1985, p. 201, p. 210). Sin embargo, diversos intérpretes señalan que, pese a la innegable influencia del liberalismo en la filosofía política kantiana, diversos aspectos obstaculizan la interpretación del filósofo como un partidario de la concepción liberal de lo político (cf. Dotti 2005, pp. 3-17; Colomer, 1994, p. 583).

19 Conocida es su divisa: "razonad como queráis y sobre lo que queráis, pero obedeced!" (Kant, I., En respuesta a la pregunta qué es ilustración, Ak., VIII, p. 41). 
Béjar, H. (2000), El corazón de la república. Avatares de la virtud política. Barcelona: Paidós.

Berlin, I. (1992), "Dos conceptos de la libertad", en A. Quinton (comp), Filosofía política. México: Fondo de Cultura Económica.

(1998), Cuatro ensayos sobre la libertad. Traducción española de B. Urrutia, J. Bayón y N. Rodríguez Salmones. Madrid: Alianza.

Bertomeu, M. J. (2005), "Las raíces republicanas del mundo moderno: en torno a Kant”, en Bertomeu, M. J.; Doménech, A., De Francisco, A., (comps.), Republicanismo y democracia. Buenos Aires: Miño y Dávila.

Bielefeldt, H. (1997), “Autonomy and Republicanism: Immanuel Kant's Philosophy of Freedom", Political Theory. 25, 5: 524-525.

Bobbio, N. (1985), Estudios de historia de la filosofia: De Hobbes a Gramsci. Traducción española de J. C. Bayón. Madrid: Debate.

(1995), Igualdad y libertad. Madrid: Paidós.

Colomer, J. L. (1994), “Algunos apuntes sobre Kant y la libertad política”, Doxa. 15: $594 \mathrm{~s}$.

Dotti, J. E. (1985), "Kant: crítica y modernidad", Punto de vista. Revista de cultura. año VII, 23: 29-34. 3-17.

(2005), “Observaciones sobre Kant y el liberalismo", Araucaria. 6,13:

Foucault, M. (1991), Saber y verdad. Traducción de J. Varela y F. Álvarez-Uría. Madrid: La Piqueta.

Kant, I. Kant's gesammelte Schriften, hrsg. von der Königlich Preussischen, bzw. der Deutschen Akademie der Wissenschaften (Ak.), Berlin et alia, 1902ss.

(1921), Fundamentación de la metafísica de las costumbres. Traducción de M. García Morente. Madrid: Espasa Calpe.

(1972), "Respuesta a la pregunta «qué es la ilustración?»", en Kant, I., Filosofía de la Historia. Traducción de E. Estiú. Buenos Aires: Editorial Nova.

(1993), Teoría y práctica. Traducción de J. M. Palacios, M. F. Pérez López y R. Rodríguez Aramayo. Madrid: Tecnos.

(1994), Metafísica de las costumbres. Traducción y notas de A. Cortina Orts y J. Conill Sancho. Madrid: Tecnos.

(1996), Sobre la paz perpetua. Traducción de J. Abellán. Madrid: Tecnos.

Kaufman, A. (1997), "Reason, Self-legislation and Legitimacy: Conceptions of Freedom in the Political Thought of Rousseau and Kant", The Review of Politics. 59, 1: 25-52.

Peña, J. (2005), “Ciudadanía republicana y virtud cívica”, en M. J., Bertomeu, Doménech, A. F. (comps.), Republicanismo y democracia. Buenos Aires: Miño y Dávila, pp. 231-256. 
Pettit, P. (2004), "Liberalismo y republicanismo”, en Ovejero, F.; Martí, J. L., Gargarella R. (comps.), Nuevas ideas republicanas. Autogobierno y libertad. Barcelona: Paidós.

Rousseau, J-J. (1996), Del contrato social. Traducción de M. Armiño. Madrid: Alianza.

Rubio-Carracedo, J. (1998), Rousseau en Kant. Bogotá: Universidad Externado de Colombia.

Savadogo, M. (1999), "Kant et la politique”, Kant Studien. 90: 306-321.

Velasco Gómez, A. (2005), "La concepción republicana de Kant”, Episteme. 25, 2 : 109-122.

Wit, E. (1990), "Kant and the Limits of Civil Obedience", Kant-Studien. 90: 285305. 